(C) 2021, The Authors. Published by Elsevier Inc. and Fass Inc. on behalf of the American Dairy Science Association ${ }^{\circledR}$. This is an open access article under the CC BY-NC-ND license (http://creativecommons.org/licenses/by-nc-nd/4.0/).

\title{
Effect of bovine feeding system (pasture or concentrate) on the oxidative and sensory shelf life of whole milk powder
}

\author{
H. J. Clarke, ${ }^{1,2}$ ๑ C. Griffin, ${ }^{3}$ D. Hennessy, ${ }^{4} \odot$ T. F. O'Callaghan, ${ }^{5} \odot$ M. G. O’Sullivan, ${ }^{2}$ J. P. Kerry, ${ }^{6}$ \\ and K. N. Kilcawley ${ }^{1 *}$ (1) \\ ${ }^{1}$ Food Quality and Sensory Science, Teagasc Food Research Centre, Moorepark, Fermoy, P61 C996, Ireland \\ ${ }^{2}$ Sensory Group, School of Food and Nutritional Sciences, University College Cork, T12 R229, Ireland \\ ${ }^{3}$ Food Industry Development, Teagasc Food Research Centre, Ashtown, Dublin 15, D15 DY05, Ireland \\ ${ }^{4}$ Teagasc Animal and Grassland Research and Innovation Centre, Moorepark, Fermoy, P61 C996 Cork, Ireland \\ ${ }^{5}$ School of Food and Nutritional Sciences, University College Cork, T12 R229, Ireland \\ ${ }^{6}$ Food Packaging Group, School of Food and Nutritional Sciences, University College Cork, T12 R229, Ireland
}

\section{ABSTRACT}

Correlating volatile compounds with the sensory attributes of whole milk powder (WMP) is fundamental for appreciating the effect of lipid oxidation (LO) on sensory perception. LO compounds can adversely affect the sensory perception of WMP by imparting rancid, metallic, and painty notes. Whole milk powders derived from milk produced by cows maintained on a pasture diet (grass and grass-clover mix) versus a nonpasture diet [total mixed ration (TMR); concentrates and silage] were stored at room temperature $21^{\circ} \mathrm{C}$ (ambient storage) and $37^{\circ} \mathrm{C}$ (accelerated storage) and analyzed for volatile compounds and sensory attributes every 2 mo for a total of 6 mo. Thirteen volatile compounds originating from $\mathrm{LO}$ were chosen to track the volatile profile of the WMP during storage. Color, composition, total fatty acid, and free fatty acid profiling were also carried out. Significant variations in the concentrations of 14 fatty acids were observed in WMP based on diet. Concentrations of free fatty acids increased in all sample types during storage. Similar trends in sensory attributes were observed with an increase in painty attributes, corresponding to an increase in hexanal. Buttery/toffee attributes were found to be more closely correlated with TMR WMP. Those WMP derived from pasture diets were found to be more susceptible to LO from a volatile perspective, particularly in relation to aldehyde development, which is likely due to increased concentrations of conjugated linoleic acid and $\alpha$-linolenic acid found in these samples.

Key words: pasture, total mixed ration, sensory, volatile, whole milk powder

Received February 14, 2021.

Accepted May 25, 2021.

*Corresponding author: Kieran.kilcawley@teagasc.ie

\section{INTRODUCTION}

Whole milk powder (WMP) is an important dairy commodity that is largely produced in countries with an abundant supply of fresh milk and exported to be reconstituted and consumed directly as a nutritious beverage or used in soups and sauces, or in baking and confectionary (Early, 2012). Spray drying enables milk to be easily transported and stored as WMP for extended periods of time. However, the spray drying process can also facilitate oxidative changes as the high fat content is exposed to elevated temperatures, resulting in reduced shelf life due to off-flavor development. Moreover, WMP can also be subjected to extreme temperature fluctuations during transport and storage, further affecting oxidative stability. Lipid oxidation is a major cause of quality deterioration in fat-containing foodstuffs, which results in alterations to taste and odor through the creation of oxidation compounds, such as aldehydes, ketones, and alcohols.

Dairy products containing increased levels of specific PUFA may be more susceptible to lipid oxidation (LO; Hedegaard et al., 2006). Bovine diet is known to influence many aspects of milk composition, but especially the fatty acid (FA) profile (Liu et al., 2016; O'Callaghan et al., 2019). Quantifying both total fatty acids (TFA) and free fatty acids (FFA) in dairy products is important (Mannion et al., 2016, 2019), to understand the potential susceptibility of dairy products to LO and to know the abundance of specific FFA that can directly contribute to flavor. Bovine milk also contains various natural oxidants and antioxidants that can also be affected by feeding system, but to date very little research has been published on the susceptibility of milk or WMP to LO dependent on bovine feeding system.

Headspace solid phase-microextraction (HS-SPME) GC-MS is a widely used technique for the identifica- 
tion and quantification of volatile compounds in dairy products (Tunick et al., 2013). A validated HS-SPME GC-MS method (Clarke et al., 2019) was used to quantify 13 compounds from 3 chemical classes (aldehydes, ketones, and alcohols) associated with LO. Quantitative descriptive analysis has previously been applied to a variety of dairy products (Stone and Sidel, 1998), and is based on the ability of trained panelists to measure specific attributes of a product (Chapman et al., 2001). This technique was employed to track the development of taste and odor attributes in WMP as LO progressed at 2 storage temperatures $\left(21^{\circ} \mathrm{C}\right.$ and $\left.37^{\circ} \mathrm{C}\right)$ in opened lidded cans. Panelists $(\mathrm{n}=9)$ were trained to rate the WMP samples based on selected relevant sensory attributes (Drake et al., 2003; Lloyd et al., 2009a,b; Park et al., 2016), which were defined and agreed upon by all panelists before final scoring. Analyses of TFA, FFA content, color, composition, sensory attributes, and volatile profile of the WMP were undertaken at 3 time points over a predefined period of 6 mo.

\section{MATERIALS AND METHODS}

\section{Milk Production}

Fifty-four lactating Friesian cows were divided into 3 groups, namely, grass-only cows (GRS), grass-clover cows $(\mathbf{C L V})$, and TMR cows $(\mathrm{n}=18)$. The GRS cows were maintained outdoors on perennial ryegrass ( $L O$ lium perenne L.) and received approximately $2 \mathrm{~kg}$ of concentrate and $15 \mathrm{~kg}$ DM of grass per cow; CLV cows were also maintained outdoors on perennial ryegrass and white clover mix (Trifolium repens $\mathrm{L}$.) and received $2 \mathrm{~kg}$ of concentrate and $15 \mathrm{~kg} \mathrm{DM}$ of grass-clover per cow; TMR cows were housed indoors and received 9 $\mathrm{kg} \mathrm{DM}$ of maize silage $+4.5 \mathrm{~kg} \mathrm{DM}$ of grass silage + $8.5 \mathrm{~kg} \mathrm{DM}$ of concentrate throughout the study. Cows within the TMR group were fed daily in electronically controlled Griffith Elder Mealmaster individual feed bins (Griffith Elder and Company Ltd.), and feed was available ad libitum. The CLV sward contained $\sim 20 \%$ white clover, as outlined by O'Callaghan et al. (2016). Cows in the GRS and CLV groups received a mineral supplement in the form of a liquid mineral preparation injected into the water supply (Terra Liquid Minerals), giving a mean intake (mg/cow per day) of $\mathrm{Na}, \mathrm{Mg}$, $\mathrm{Zn}, \mathrm{Cu}$, Se, and Co of 5.0,1.2, 219, 106, 3.8, and 3.0, respectively. The concentrate portion of the TMR feed was supplemented with a commercial mineral balancer (Dairy Hi-Phos; McDonnell Bros. Agricultural Suppliers Ltd.) to give added $\mathrm{Ca}, \mathrm{Na}, \mathrm{P}, \mathrm{Zn}, \mathrm{Cu}, \mathrm{Mn}, \mathrm{I}, \mathrm{Co}$, and Se of 3,340, 2000, 1200, 140, 100, 70, 10, 2, and 0.8 $\mathrm{mg} / \mathrm{kg}$, respectively (Gulati et al., 2018).

\section{Manufacture of WMP}

Medium-heat WMP was produced in triplicate from milk from each group $(\mathrm{n}=18)$ at Moorepark Technology Limited BioFunctional Food Engineering pilot plant (Teagasc, Moorepark, Fermoy, Co. Cork, Ireland) over a 3-wk period in May 2019. Raw whole milk was collected both morning and evening from each group (GRS, CLV, and TMR) for 3 consecutive days, and each batch $(\sim 1,000 \mathrm{~kg})$ was preheated to $50^{\circ} \mathrm{C}$ and pasteurized at $90^{\circ} \mathrm{C}$ for $30 \mathrm{~s}$ in an APV plate heat-exchanger (SPX Flow Technology), before homogenization using an APV-Gaulin 2-stage homogenizer at first- and second-stage pressures of 150 and 50 bar, respectively. The homogenized milk was evaporated to $\sim 40 \%$ TS in a single-effect recirculating evaporator (Scheffers). The concentrate was preheated to $65^{\circ} \mathrm{C}$ in a plate heatexchanger and transferred to an Anhydro 3-stage spray dryer (SPX Flow Technology Denmark A/S; air inlet temperature $170^{\circ} \mathrm{C}$; air outlet temperature $65^{\circ} \mathrm{C}$ ). First and second fluid bed temperatures were set at $65^{\circ} \mathrm{C}$ and $25^{\circ} \mathrm{C}$, respectively. Fines were returned to the top of the spray dryer from the second fluid bed and the cyclone, yielding an agglomerated WMP of approximately $97 \%$ TS. Production of WMP from each feeding system was carried out in triplicate from 3 independent raw milk collections outlined previously (Magan et al., 2019). All equipment was cleaned thoroughly between batches. All WMP were packed in 400-g aluminum cans, flushed with $\mathrm{N}_{2}$, and sealed immediately. The WMP produced from grass-only, grass-clover, and TMR milk were denoted as GRS, CLV, and TMR, respectively. All results reported are the averages of triplicate analysis of the 3 production batches for GRS, CLV, and TMR powders $(\mathrm{n}=9)$ unless otherwise stated.

\section{Shelf Life Study Design}

The fresh WMP produced from each feeding system were split into 2 storage groups, $21^{\circ} \mathrm{C}$ and $37^{\circ} \mathrm{C}$; this resulted in 6 samples in total, denoted GRS $21^{\circ} \mathrm{C}$, GRS $37^{\circ} \mathrm{C}, \mathrm{CLV} 21^{\circ} \mathrm{C}$, CLV $37^{\circ} \mathrm{C}$, TMR $21^{\circ} \mathrm{C}$, and TMR $37^{\circ} \mathrm{C}$. All sample cans were opened at T0, and initial sensory and volatile measurements were taken. The opened cans were used for all subsequent analysis throughout the study, and plastic lids were placed on the open cans (closed but not sealed) while in storage (Cesa et al., 2015 ), to best reflect typical use in a domestic environment. The time points chosen for analysis of WMP color, volatile profile, and sensory perception were 0 (T0), 2 (T2), 4 (T4), and 6 (T6) mo. The FFA content was assessed at T0, T4, and T6, whereas TFA content and WMP composition were assessed at T0 only. 


\section{Color Measurements}

Color measurements were performed on the GRS, CLV, and TMR WMP stored at $21^{\circ} \mathrm{C}$ and $37^{\circ} \mathrm{C}$ at each time point according to the CIE Lab system (CIE, 1978; $\mathrm{L}^{*}$ is a measure of lightness; $\mathrm{a}^{*}$ is a measure of green-to-red color on a negative-to-positive scale, respectively, and $\mathrm{b}^{*}$ is a measure of blue-to-yellow color on a negative-to-positive scale, respectively), using a Minolta colorimeter (Minolta Camera). All WMP were reconstituted to $12 \%$ TS using distilled water $\left(\mathbf{d H}_{2} \mathbf{O}\right)$ $24 \mathrm{~h}$ before analysis and chilled at $4^{\circ} \mathrm{C}$. Approximately $2 \mathrm{~mL}$ of sample was placed in a spectrophotometric cuvette and allowed to stabilize at room temperature for 30 min before analysis, as per Faulkner et al. (2018). Results were expressed as the average of triplicate measurements of each liquid sample.

\section{Powder Composition}

Each WMP was analyzed for fat, protein, lactose, true protein, and casein content directly after manufacture (T0) using a Bentley DairySpec FT (Technopath Distribution). The WMP samples were reconstituted to $3.5 \%$ fat using $\mathrm{dH}_{2} \mathrm{O}$, as per the equation outlined by the International Dairy Federation (IDF, 1997) $24 \mathrm{~h}$ before analysis. Results were expressed as the averages of 2 replicates.

\section{Fatty Acid Profiling}

Free Fatty Acid Profiling. Analysis of FFA was carried out on the GRS, CLV, and TMR WMP at T0, $\mathrm{T} 4$, and $\mathrm{T} 6 \mathrm{mo}$ of storage at $21^{\circ} \mathrm{C}$ and $37^{\circ} \mathrm{C}$. Lipid extraction, butyl ester derivatization of triglycerides, solid-phase extraction and gas chromatography instrument conditions were performed as per Mannion et al. (2019). Each powder (4 g) was analyzed in duplicate, and the extracts were pooled for solid-phase extraction.

Total Fatty Acid Profiling. Profiling of TFA was carried out on the GRS, CLV, and TMR WMP at T0. Lipid extraction and methyl ester derivatization of triglycerides were carried out as per De Jong and Badings (1990) and O'Callaghan et al. (2019). The WMP were reconstituted to $12 \%$ TS using $\mathrm{dH}_{2} \mathrm{O} 1 \mathrm{~h}$ before analysis, and $10 \mathrm{~mL}$ of reconstitute was used for analysis. The GC conditions were also outlined by O'Callaghan et al. (2019). Briefly, analysis was performed on an Agilent 7890A GC, equipped with an Agilent 7693 autosampler (Agilent Technologies Ltd.) and flame ionization detector. The column was a Select FAME capillary column $(100 \mathrm{~m} \times 250-\mu \mathrm{m}$ internal diameter, $0.25-\mu \mathrm{m}$ phase thickness; part number CP7420; Agilent Technologies Ltd.). The injector was held at $250^{\circ} \mathrm{C}$ for the entire run and was operated in split mode using a split ratio of $1: 10$. The column oven was held at $80^{\circ} \mathrm{C}$ for $8 \mathrm{~min}$, raised to $200^{\circ} \mathrm{C}$ at $8.5^{\circ} \mathrm{C} / \mathrm{min}$, and held for $55 \mathrm{~min}$. The total runtime was $77.12 \mathrm{~min}$. The flame ionization detector was operated at $300^{\circ} \mathrm{C}$. Results were processed using OpenLab CDS Chemstation edition software version Rev.C.01.04 (35) (Agilent Technologies Ltd.).

A 37-component FAME reference mix containing C4:0 to C24:0 (part number 35077; Thames Restek UK Ltd.) was analyzed as an in-run quality control sample, with the FAME present at concentrations of 60 to 180 $\mathrm{mg} / \mathrm{kg}$. This was used to ensure that accurate quantification was being achieved throughout sample analysis. The FAME mix was analyzed once every 5 samples in the sequence. Accuracy was monitored by comparing the measured concentration of this FAME mix against its true concentration.

\section{Sensory Evaluation}

Quantitative descriptive analysis was carried out on the WMP in Teagasc Ashtown (Dublin, Ireland). An external trained sensory panel consisting of 9 members was recruited, based on their ability to perceive a wide variety of attributes and their continued availability. Panelists had between 3 and 4 yr experience working as descriptive panelists on a weekly basis. Panel training for WMP evaluation consisted of 2 attribute generation sessions ( $3 \mathrm{~h}$ duration each), wherein the panelists evaluated a variety of volatile compounds on cotton wool (Supplemental Table S1, http://hdl.handle.net/ 11019/2424) in addition to the use of 12 Sniffing Sticks (cardboard, rancid, butter, soapy, musty/cellar, cheesy/ sweaty, mushroom, earthy, malty, cabbage, animal/stable, and fishy; Dohler GmbH) designed specifically for this study. A further 4 sessions of panel training were carried out using a variety of product standards to create aroma, texture, flavor, and aftereffect scales for each sensory descriptor that was subsequently applied to the GRS, CLV, and TMR WMP (Supplemental Table S2, http://hdl.handle.net/11019/2424). Panelists used the consensus list of descriptors for scoring, measured on a scale of 1 to 10 with 1 to 3 considered low intensity, 4 to 7 considered medium intensity, and 8 to 10 considered high intensity. Triangle tests were used before the final scoring to ensure that panelists were performing within expectations. The WMP were reconstituted 24 $\mathrm{h}$ before scoring based on the fat and protein content (IDF, 1997) using $\mathrm{dH}_{2} \mathrm{O}$ and were stored at $2^{\circ} \mathrm{C}$ until approximately $1 \mathrm{~h}$ before each training and scoring session. Samples were allowed to reach 11 to $12^{\circ} \mathrm{C}$ before serving. The reconstituted WMP were gently stirred and poured into $20-\mathrm{mL}$ clear plastic cups, which were labeled with random 3-digit codes. Panelists were given 
water and plain crackers or green apples to cleanse the palate between samples. The project was set up as a complete block design using Compusense 5.6 (sensory data capture package, https://compusense.com/). The WMP were scored in triplicate for each trial replicate (GRS, CLV, and TMR), for each descriptor, and the results were averaged $(\mathrm{n}=9)$. Analysis of color was also carried out by the panelists on each WMP.

\section{Volatile Analysis}

Thirteen volatile aromatic compounds including 7 aldehydes [hexanal, pentanal, heptanal, octanal, (E)2-nonenal, 2,4-decadienal, undecanal], 4 ketones (2-heptanone, 2-nonanone, 2-pentanone, 3-octen-2-one), and 2 alcohols (1-heptanol and 1-pentanol) known to be important to the sensory perception of dairy products were selected for quantification based on current literature (Van Aardt et al., 2005; Faulkner et al., 2018; Kilcawley et al., 2018). Authentic standards for each of the compounds were obtained from Merck Ireland and stored at room temperature. All standard solutions for HS-SPME GCMS analysis were prepared at $0.1 \%$ (wt/ vol) in methanol and stored at $-18^{\circ} \mathrm{C}$ until required for analysis, but for no longer than 6 mo. For all calibration curves the external standard mixture was prepared at $0.004 \%$ (wt/vol; $4 \mathrm{~mL}$ in $100 \mathrm{~mL}$ of $\mathrm{dH} 2 \mathrm{O}$ ) and the internal standard mixture (2-methyl-3-heptanone, 4-methyl-2-pentanol, and isovaleraldehyde) was prepared at $0.001 \%\left(\mathrm{wt} / \mathrm{vol} ; 1 \mathrm{~mL}\right.$ in $100 \mathrm{~mL}$ of $\mathrm{dH}_{2} \mathrm{O}$ ). For the preparation of calibration curves, varying levels of the standard mixture were prepared in $10-\mathrm{mL}$ volumetric flasks with $\mathrm{dH}_{2} \mathrm{O}$.

The HS-SPME GCMS analysis was carried out as described by Clarke et al. (2019) at T0, T2, T4, and T6 sampling points. Briefly, WMP (2.40 g) was weighed out directly into an amber La-Pha-Pack headspace vials $(20 \mathrm{~mL})$ with magnetic caps and silicone/ polytetrafluoroethylene $1.3-\mathrm{mm} 45^{\circ}$ Shore A septa (Apex Scientific Ltd.). Then $\mathrm{dH}_{2} \mathrm{O}(2.50 \mathrm{~g})$ and 250 $\mu \mathrm{L}$ of $0.001 \%$ (wt/vol) internal standard were added to each sample. A calibration curve was also prepared by spiking a set of the reconstituted WMP samples with varying levels of the external standard mixture. Matrix (control) samples (WMP sample $+\mathrm{dH}_{2} \mathrm{O}$ only) were also included in each run. Samples were incubated for $45 \mathrm{~min}$ at a temperature of $43^{\circ} \mathrm{C}$ using a CombiPal agitator/heater module (Elementec Ltd.), followed by a 10-min pre-extraction incubation time with pulsed agitation of $5 \mathrm{~s}$ at $500 \mathrm{rpm}$. Each sample was analyzed in triplicate at each time point.

\section{Statistical Analysis}

Statistical analysis for data relating to color and composition was carried out using one-way ANOVA with post-hoc Tukey tests using SPSS software, version 24 (IBM Corp.). Pearson correlation analysis was carried out on the sensory and volatile data using SPSS. Principal component analysis biplots of the volatile versus sensory data were constructed using the factoextra and FactoMinoR packages within R (v. 3.4.1; R Core Team, 2013). All sensory and volatile data were averaged before analysis.

\section{RESULTS AND DISCUSSION}

\section{Milk Color}

The TMR WMP scored significantly $(P<0.05)$ lower for $\mathrm{a}^{*}$ and $\mathrm{b}^{*}$ values compared with the GRS and CLV WMP at each time point (Table 1). The TMR WMP scored significantly $(P<0.05)$ higher for $\mathrm{L}^{*}$ values at $\mathrm{T} 0$ and T2, and, although not statistically different at T4 and T6, L* values remained higher than GRS and CLV WMP. These results were in agreement with previous studies on dairy products produced from pasture versus concentrate-based feeding systems (Faulkner et al., 2018; Clarke et al., 2020a). The significant differences in color between pasture-derived dairy products and those derived from concentrate has previously been attributed to the abundance of $\beta$-carotene in pasture forages, which results in a more yellow or creamy color (Martin et al., 2005). This study corroborates these results with TMR samples scoring significantly $(P<$ 0.05) higher for white color, whereas pasture-derived products (GRS and CLV) were scored higher for creamy color by the sensory panel. The TMR WMP also scored significantly $(P<0.05)$ lower for $\mathrm{a}^{*}$ and $\mathrm{b}^{*}$ values compared with the GRS and CLV powders at each time point. Lightness also varied significantly $(P$ $<0.05$ ) between the 3 WMP at T0 and T2. Although lightness was not statistically significant at T4 and T6, similar trends in lightness were observed between the different types of WMP, with slight increases observed. The $\mathrm{b}^{*}$ values (blue-to-yellow) also increased slightly in all 3 WMP from T0 to T6, possibly due to Maillard browning reactions occurring during storage (Bastos et al., 2012). The rate of Maillard browning is known to be affected by several factors, including the chemical nature of the reactants (type of amine and carbonyl groups), water activity, $\mathrm{pH}$, temperature, heating time, and protein-to-sugar ratio (Labuza and Baiser, 1992; Rozycki et al., 2007). 
Table 1. Results of color measurements $(\mathrm{n}=3)$ taken of the 3 reconstituted whole milk powders derived from milk from cows fed perennial ryegrass (GRS), perennial ryegrass and white clover (CLV), or TMR at times (T) $0,2,4$, and 6 mo of storage at $21^{\circ} \mathrm{C}$ and $37^{\circ} \mathrm{C}^{1}$

\begin{tabular}{llll}
\hline Sample & $\mathrm{L}^{*}$ & $\mathrm{a}^{*}(-)$ & $\mathrm{b}^{*}$ \\
\hline T0 & & & \\
GRS & $80.97^{\mathrm{c}}$ & $3.24^{\mathrm{a}}$ & $7.24^{\mathrm{a}}$ \\
CLV & $82.16^{\mathrm{b}}$ & $3.24^{\mathrm{a}}$ & $6.96^{\mathrm{a}}$ \\
TMR & $83.26^{\mathrm{a}}$ & $2.84^{\mathrm{b}}$ & $4.86^{\mathrm{b}}$ \\
T2 & & & \\
GRS $21^{\circ} \mathrm{C}$ & $86.02^{\mathrm{b}}$ & $3.51^{\mathrm{a}}$ & $8.11^{\mathrm{a}}$ \\
CLV $21^{\circ} \mathrm{C}$ & $85.94^{\mathrm{b}}$ & $3.32^{\mathrm{a}}$ & $7.75^{\mathrm{a}}$ \\
TMR $21^{\circ} \mathrm{C}$ & $86.56^{\mathrm{a}}$ & $2.86^{\mathrm{b}}$ & $6.37^{\mathrm{b}}$ \\
GRS $37^{\circ} \mathrm{C}$ & $85.40^{\mathrm{b}}$ & $3.51^{\mathrm{a}}$ & $8.02^{\mathrm{a}}$ \\
CLV $37^{\circ} \mathrm{C}$ & $85.88^{\mathrm{b}}$ & $3.49^{\mathrm{a}}$ & $7.84^{\mathrm{a}}$ \\
TMR $37^{\circ} \mathrm{C}$ & $86.14^{\mathrm{a}}$ & $2.91^{\mathrm{b}}$ & $5.62^{\mathrm{b}}$ \\
T4 & & & \\
GRS $21^{\circ} \mathrm{C}$ & 85.92 & $3.39^{\mathrm{a}}$ & $8.04^{\mathrm{a}}$ \\
CLV $21^{\circ} \mathrm{C}$ & 85.58 & $3.35^{\mathrm{a}}$ & $7.38^{\mathrm{a}}$ \\
TMR $21^{\circ} \mathrm{C}$ & 86.02 & $2.59^{\mathrm{b}}$ & $5.28^{\mathrm{b}}$ \\
GRS $37^{\circ} \mathrm{C}$ & 85.72 & $3.41^{\mathrm{a}}$ & $8.01^{\mathrm{a}}$ \\
CLV $37^{\circ} \mathrm{C}$ & 82.64 & $3.35^{\mathrm{a}}$ & $7.73^{\mathrm{a}}$ \\
TMR $37^{\circ} \mathrm{C}$ & 85.67 & $2.58^{\mathrm{b}}$ & $5.38^{\mathrm{b}}$ \\
T6 & & & \\
GRS $21^{\circ} \mathrm{C}$ & 85.49 & $3.40^{\mathrm{a}}$ & $7.77^{\mathrm{a}}$ \\
CLV $21^{\circ} \mathrm{C}$ & 82.52 & $3.28^{\mathrm{a}}$ & $7.55^{\mathrm{a}}$ \\
TMR $21^{\circ} \mathrm{C}$ & 85.87 & $2.72^{\mathrm{b}}$ & $5.41^{\mathrm{b}}$ \\
GRS $37^{\circ} \mathrm{C}$ & 84.90 & $3.52^{\mathrm{a}}$ & $7.55^{\mathrm{a}}$ \\
CLV $37^{\circ} \mathrm{C}$ & 84.97 & $3.43^{\mathrm{a}}$ & $7.51^{\mathrm{a}}$ \\
TMR $37^{\circ} \mathrm{C}$ & 85.06 & $2.78^{\mathrm{b}}$ & $5.21^{\mathrm{b}}$ \\
\hline
\end{tabular}

${ }^{\mathrm{a}-\mathrm{c}}$ Mean values in the same column (analyzed by time point: T0, T2, T4, T6, representing $0,2,4$, and 6 mo) with different superscripts differ $(P<0.05)$ based on feeding system.

${ }^{1}$ Each result is the average of triplicate analysis of WMP derived the from 3 production trials for GRS-, CLV-, and TMR-based feeding systems $(n=9) . L^{*}$ is a measure of lightness; $a^{*}$ is a measure of green-tored color on a negative-to-positive scale, respectively; $b^{*}$ is a measure of blue-to-yellow color on a negative-to-positive scale, respectively. All $\mathrm{a}^{*}$ values are negative, indicated by $(-)$.

\section{Milk Powder Composition}

No significant differences were observed between the fat, protein, lactose, true protein, and casein contents of the GRS, CLV, and TMR WMP analyzed directly after manufacture at T0 (Supplemental Table S3).

\section{Fatty Acid Profiling}

Free Fatty Acid Profiling. Levels of FFA in the WMP were quantified at T0, T4, and T6. Results showed that C16:0 (palmitic acid) was the most abundant FFA in all sample types at T0 $(62-67 \mathrm{mg} / \mathrm{kg})$, followed by C18:0 (stearic acid; $33-38 \mathrm{mg} / \mathrm{kg}$ ), and C18:1 (oleic acid; 26-32 mg/kg; Table 2). The concentrations of FFA in the GRS, CLV, and TMR WMP did not vary significantly $(P<0.05)$ at T0. However, increases in C16:0, C18:0, and C18:1 were observed in all $3 \mathrm{WMP}$ from T0 to T6. Significant $(P<0.001)$ increases in the concentrations of C18:0 were observed in CLV and TMR WMP from T4 to T6. Increases in the total FFA content were also observed in all WMP from T0 to T6. The levels of individual FFA in the GRS, CLV, and TMR WMP were comparable to those reported by Páez et al. (2006).

Certain FA are directly responsible for off-flavors such as rancid, astringent, and butyric (Deeth 2006), but, perhaps more importantly from a sensory standpoint, FA are precursors of oxidation reactions resulting in the production of aldehydes and ketones, which are responsible for oxidized, metallic, and tallowy off-flavors often observed in milk powders (Muir, 1996; Páez et al., 2006). It has been speculated that powders derived from pasture may be more susceptible to LO due to the increased presence of PUFA such as arachidonic acid and docosahexaenoic acid (Kilcawley et al., 2018); however, it has been noted that the presence or concentration of natural antioxidants and pro-oxidants are also major factors (Romeu-Nadal et al., 2004).

Total Fatty Acid Profiling. A total of 29 FA were quantified (g/100 $\mathrm{g}$ of milk fat) in the WMP. It was evident that feeding system had a significant $(P=$ 0.05 ) effect on the concentrations of 14 of the $29 \mathrm{FA}$ quantified in the WMP, which is in agreement with previous studies on milk and WMP (Semeniuc et al., 2008; O'Callaghan et al., 2016). The 14 FA that varied significantly $(P<0.05)$ based on feeding system were undecanoic acid (C11:0), tridecanoic acid (C13:0), myristoleic acid (C14:1), pentadecanoic acid (C15:0), palmitic acid (C16:0), trans-9,12-octadecadienoate (C18:2n-6t), $\alpha$-linolenic acid (C18:3n-3), $\gamma$-linolenic acid (C18:3n-6), eicosanoic acid (C20:0), eicosenoic acid (C20:2), eicosapentaenoic acid (C20:5), heneicosanoic acid (C21:0), CLA (c10t12), and CLA (c9t11; Table 3).

As previously reported in milk (O'Callaghan et al., 2016), palmitic acid (C16:0) and oleic acid (C18:1n-9c) were found to be the most abundant FA in all WMP analyzed. Average palmitic acid content was highest in TMR powders $(29.94 \pm 2.98)$, significantly $(P<0.05)$ higher than in GRS $(24.96 \pm 0.90)$ and CLV $(25.06 \pm$ $0.28)$ WMP. The concentration of oleic acid (C18:1n9c) did not vary significantly between the WMP in this study at T0. Higher proportions of CLA have previously been reported in milk from cows consuming significant quantities of grazed grass than cows whose diet primarily consists of conserved forages and concentrates (Kelly et al., 1998). The significantly $(P<0.05)$ higher proportions of CLA observed in pasture-derived WMP (GRS and CLV) agrees with studies on milk and cheese from the same feeding systems used in this study (O'Callaghan et al., 2016, 2017). 


\section{Sensory Evaluation}

White color was more closely associated with TMR WMP, whereas creamy color was associated with pasture-derived (GRS and CLV) WMP. At T0, significant $(P<0.001)$ differences were observed for color, dairy sweet aroma, buttery/toffee aroma, and buttery/toffee flavor between the different WMP samples. The attribute dairy sweet aroma was higher in GRS and CLV WMP, with buttery/toffee aroma and flavor higher in TMR WMP. The white color association with the TMR WMP observed by panelists is in agreement with the instrumental color analysis. At T2, the differences between the WMP were more apparent for both storage temperatures $\left(21^{\circ} \mathrm{C}\right.$ and $\left.37^{\circ} \mathrm{C}\right)$. At T2 cooked milk aroma, dairy sweet flavor, cooked milk flavor, and dairy sweet aftereffect varied significantly $(P<0.05)$ between the different WMP.

For the pasture-derived WMP (GRS and CLV), creamy flavor and dairy sweet flavor dominated at T0. However, a barnyard/cowy aroma and flavor, cooked milk aroma, and hay-like flavor and aroma were to the fore at T2. An increase in painty flavor and astringency were observed in GRS and CLV WMP stored at $37^{\circ} \mathrm{C}$ at $\mathrm{T} 4$ and $\mathrm{T} 6$, which corresponded with an increase the concentration of all volatile compounds. The increases in painty flavor and painty flavor aftereffect were more pronounced in CLV WMP compared with GRS WMP samples (Figure 1A and B). In TMR WMP, the pleasant attributes that are commonly associated with fresh reconstituted WMP (creamy and dairy sweet) were dominant at T0. At T2, buttery/toffee and hay-like flavors became more pronounced in both TMR $21^{\circ} \mathrm{C}$ and TMR $37^{\circ} \mathrm{C}$. At T4, dairy sweet aroma remained, but metallic off-flavors began to be perceived. At T6, painty flavor and solvent-like aroma dominated in TMR WMP stored at $37^{\circ} \mathrm{C}$, whereas metallic flavor and cooked milk aroma were to the fore in TMR WMP stored at $21^{\circ} \mathrm{C}$ (Figure 1C). When comparing the $3 \mathrm{WMP}$ (GRS, CLV, and TMR) dairy sweet flavor, creamy flavor, creaminess, and viscosity were associated with all $3 \mathrm{WMP}$ samples at T0. Barnyard/cowy aroma, hay-like aroma, and hay-like flavor were more closely correlated with the GRS and CLV WMP at T2, whereas painty aroma, painty flavor, and painty flavor aftereffect were more correlated with TMR samples stored at $37^{\circ} \mathrm{C}$ at $\mathrm{T} 6$.

The ability of the sensory panelists to identify and rate the intensity of a painty flavor and aroma in some WMP suggests that the levels of volatile aromatic compounds responsible for this attribute had increased above their odor thresholds over the 6-mo storage period. For example, hexanal, derived primarily from linoleic acid, has been shown to be responsible for a painty off-flavor in milk powders (Lloyd et al., 2009a; Clarke et al., 
Table 3. Mean fatty acid composition of whole milk powders ( $\mathrm{g} / 100 \mathrm{~g}$ of milk fat $\pm \mathrm{SD}$ ) produced from milk from cows fed perennial ryegrass (GRS), perennial ryegrass and white clover $(\mathrm{CLV})$, or $\mathrm{TMR}^{1}$

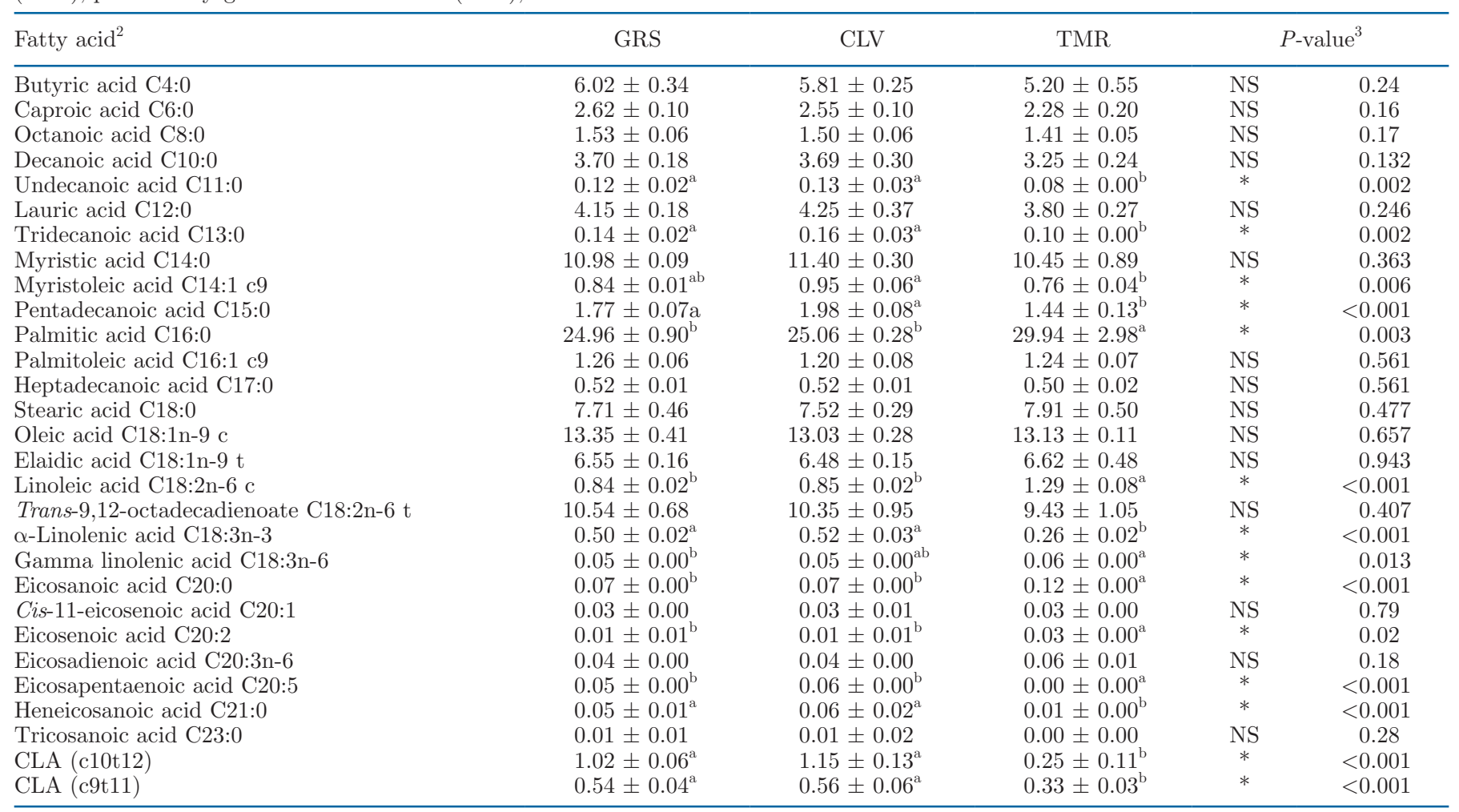

${ }^{\mathrm{a}, \mathrm{b}}$ Mean values in the same row with different superscripts differ $(P=0.05)$ based on feeding system.

${ }^{1}$ Each result is the average of duplicate analysis of WMP derived the from 3 production trials for GRS-, CLV-, and TMR-based feeding systems $(\mathrm{n}=6)$. Statistical analysis was carried out by one-way ANOVA.

${ }^{2} \mathrm{c}=$ cis; $\mathrm{t}=$ trans.

${ }^{3} \mathrm{NS}=$ not significant.

*Significant differences in fatty acid composition when $P=0.05$.

2020b) and was present in GRS, CLV, and TMR WMP at highest concentrations $(1,957,2,092$, and $1,791 \mathrm{mg} /$ $\mathrm{kg}$, respectively) at $\mathrm{T} 6$ stored at $37^{\circ} \mathrm{C}$. Concentrations of pentanal and heptanal were also significantly $(P<$ 0.05) higher in the GRS and CLV WMP compared with the TMR WMP, possibly due to the greater amount of linoleic acid present in the GRS and CLV WMP samples. The odor threshold $(\mathrm{mg} / \mathrm{kg})$ in an oil matrix for hexanal, pentanal, and heptanal has been reported as 320,240 , and $3,200 \mathrm{mg} / \mathrm{kg}$, respectively (Decker et al., 2010). Thus, hexanal and pentanal were present at $>4$ times their odor threshold in all WMP stored at $37^{\circ} \mathrm{C}$ at $\mathrm{T} 6$, which may likely explain the increase in painty attributes. Heptanal increased above its odor threshold in CLV WMP stored at $37^{\circ} \mathrm{C}$ at $\mathrm{T} 4$ and $\mathrm{T} 6$ (4,325 and 4,409, respectively). Levels of heptanal were also more abundant in GRS WMP stored at $37^{\circ} \mathrm{C}$ at T4 and T6 (2,937 and 2,994, respectively) but likely below its odor threshold.

Panelists identified a dominant buttery/toffee note in all WMP samples, which decreased over time, as a painty aroma and flavor became more dominant (Figure $2 \mathrm{~A}-\mathrm{F}$ ). This trend was particularly evident in TMR WMP, where the increase in the painty aroma and flavor was strongly correlated with increases in the concentrations of hexanal (Figure 2E and 2F). Hexanal, heptanal, and octanal have previously been found to be good predictors of painty and grassy flavors in WMP (Lloyd et al., 2009a). Hexanal reached similar concentrations across all $3 \mathrm{WMP}$, but the associated painty flavor was more readily identifiable in TMR WMP at T6, as the buttery/toffee notes declined. Thus, it appears that other volatile compounds must also contribute to painty flavor or possibly are masking painty flavor. Maillard and caramelization reactions have been shown to produce caramel-like and toffee-like flavors in dairy products (Patton, 1955), likely enhanced by the spray drying process. The strong association of the buttery/toffee attribute with the TMR WMP may be the result of more Maillard or oxidative browning, which was subsequently masked by the production of LO products over storage. 

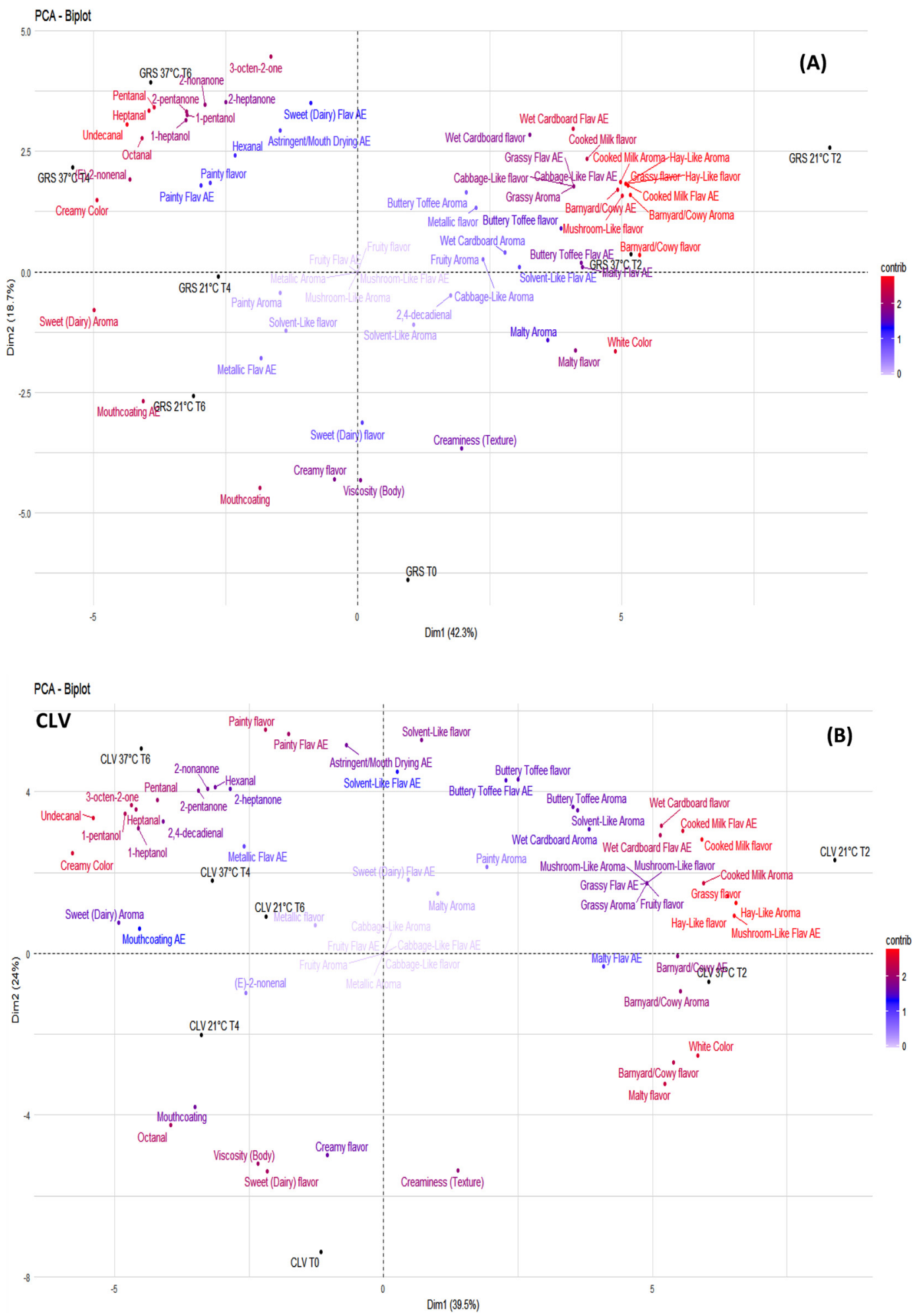

Figure 1. (A) Principal component analysis (PCA) biplot, representing the correlation structure of the variables (sensory attributes identified by full descriptive analysis and volatile compounds identified by headspace solid-phase microextraction gas chromatography mass spectrometry) and the relationship between the whole milk powder samples derived from grass (GRS) from times (T) 0-6 mo. (B) PCA biplot analysis of the variables and the milk powder samples derived from perennial ryegrass and white clover (CLV) from T0-T6. (C) PCA biplot analysis of the variables and the milk powder samples derived from TMR from T0-T6. Color gradient: low $=$ white, mid = blue, high $=$ red; midpoint set at 1.0. Flav $=$ flavor; $\mathrm{AE}=$ aftereffect. Dim $=$ dimension 
Pearson correlation relationships indicated that the sensory attributes hay-like aroma and flavor, grassy aroma and flavor, and barnyard/cowy aroma and flavor can be grouped together, and therefore an increase in one attribute indicates that all increase. However, this could also indicate that all 3 attributes may have had similar identification criteria by the sensory panel. Additionally, buttery/toffee aroma and flavor were consistently correlated with dairy sweet attributes. Another group of attributes that were correlated were painty, solvent-like, and metallic aromas, flavors, and aftereffects. Specific individual volatile aldehydes, ketones, and alcohols are good indicators of how their overall chemical classes behave during the LO process. Therefore, an increase of one compound within a chemical class can indicate that others within that class derived from the same process, such as LO, will also increase. The increased concentrations of the alcohol compounds 1-heptanol and 1-pentanol observed in GRS and CLV WMP were very likely directly associated with the levels of precursors heptanal and pentanal, respectively (Kilcawley et al., 2018).

\section{Volatile Analysis}

The highest concentrations of the aldehyde compounds hexanal, pentanal, and heptanal were observed in GRS and CLV WMP stored at $37^{\circ} \mathrm{C}$ at $\mathrm{T} 4$ and $\mathrm{T} 6$ $(>1,500 \mathrm{mg} / \mathrm{kg}$; Figure 3B and 3D). These compounds were consistently higher in GRS and CLV WMP compared with TMR WMP. Aldehydes ( $\geq 8$ carbons) and branched-chain aldehydes were best correlated with CLV WMP. The ketone compounds 2-nonanone, 2-heptanone, 2-pentanone, and 3-octen-2-one were consistently higher in GRS and TMR WMP samples stored at $37^{\circ} \mathrm{C}$ throughout the study, whereas the alcohol compounds 1-heptanol and 1-pentanol were highest in GRS and CLV WMP stored at $37^{\circ} \mathrm{C}$. One-way ANOVA analysis with post hoc Tukey's test showed significant $(P<0.001)$ increases in the concentrations of hexanal, heptanal, 2-nonanone, 2-heptanone, 2-pentanone, 3-octen-2-one, and 1-pentanol in all the WMP from $\mathrm{T} 0$ to $\mathrm{T} 6$.

Increases in the concentrations of hexanal, pentanal, heptanal, octanal, 2,4-decadienal, undecanal, and

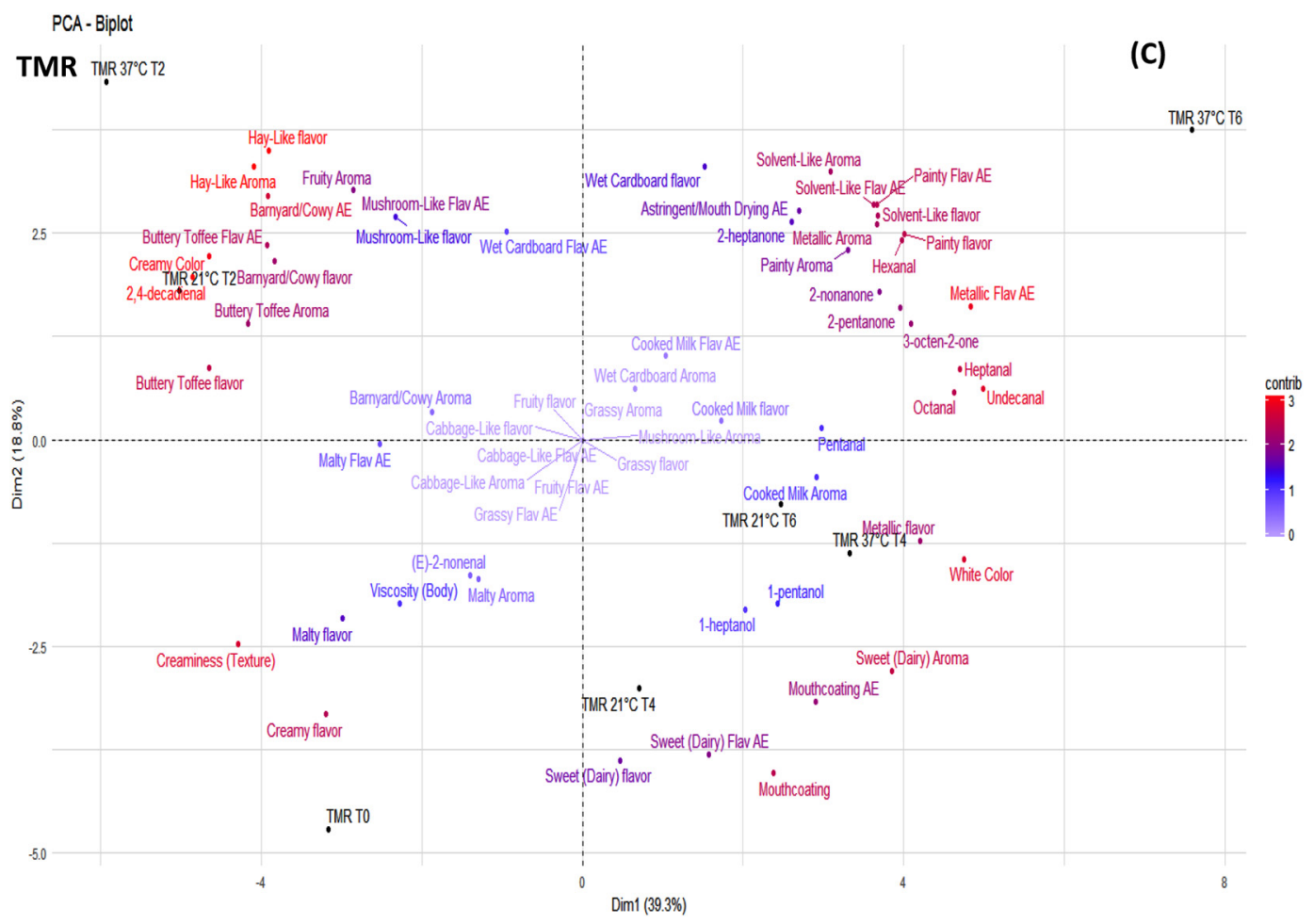

Figure 1 (Continued). (A) Principal component analysis (PCA) biplot, representing the correlation structure of the variables (sensory attributes identified by full descriptive analysis and volatile compounds identified by headspace solid-phase microextraction gas chromatography mass spectrometry) and the relationship between the whole milk powder samples derived from grass (GRS) from times (T) 0-6 mo. (B) PCA biplot analysis of the variables and the milk powder samples derived from perennial ryegrass and white clover (CLV) from T0-T6. (C) PCA biplot analysis of the variables and the milk powder samples derived from TMR from T0-T6. Color gradient: low $=$ white, mid $=$ blue, high $=$ red; midpoint set at 1.0. Flav = flavor; $\mathrm{AE}=$ aftereffect. Dim $=$ dimension. 
2-pentanone were observed in the GRS WMP stored at $21^{\circ} \mathrm{C}$ from $\mathrm{T} 0$ to $\mathrm{T} 4$. After T4, hexanal was the only compound that continued to increase; all the other compounds either remained at the same concentration or decreased slightly (Figure $3 \mathrm{~A}$ and Supplemental Table S4A, http://hdl.handle.net/11019/2424), a trend that has been observed previously in WMP after 10 mo of storage (Lloyd et al., 2009b) and in whey protein concentrate after 4 mo of storage (Javidipour and Qian, 2008). The decrease in certain volatile compounds after they have peaked has previously been attributed to their degradation or catabolism (Neilson et al., 2006; Wright et al., 2009). Other studies have speculated that proteins, flavonoids, and some enzymes such as superoxide dismutase can inhibit LO by antioxidant activity (Eriksson 1982). The same study stated that LO inhibitors induced by thermal processing, such as Maillard reaction products and native protein hydrolysates, may also be factors in inhibiting the LO mechanism. In addition to flavonoids, $\beta$-carotene has the potential to protect dairy products against oxidation (Havemose et al., $2006)$. As previously mentioned, $\beta$-carotene is known to be higher in dairy products produced from pasture and is responsible for their greater yellow color compared with those derived from TMR systems. Strecker-type degradation of amino acids has also been shown to be produced by some LO products (Hidalgo and Zamora, 2004), which may indicate the consumption of some LO end products in these reactions. A decrease in water activity within WMP during storage may also inhibit $\mathrm{LO}$ reaction rates.

In GRS WMP stored at $37^{\circ} \mathrm{C}, 4$ aldehydes, namely hexanal, pentanal, heptanal, and undecanal, continued to increase from T4 to T6. The other 8 volatile

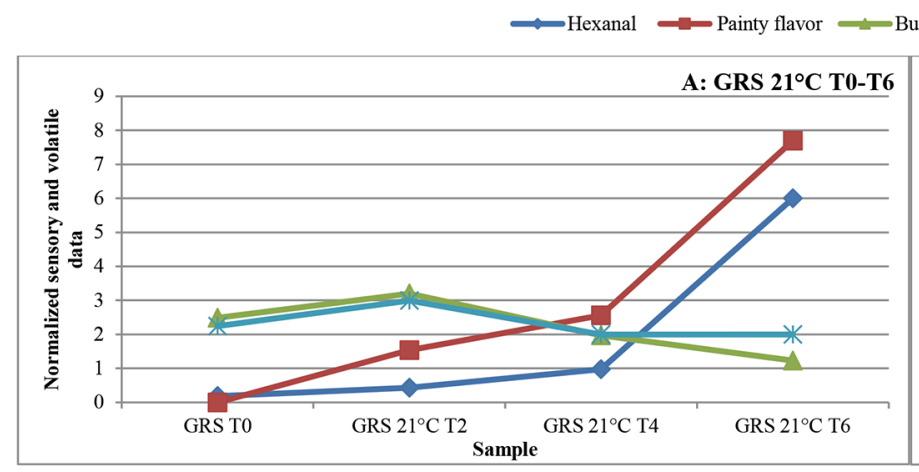

Buttery/toffee flavor $\ldots$ Buttery/toffee aroma
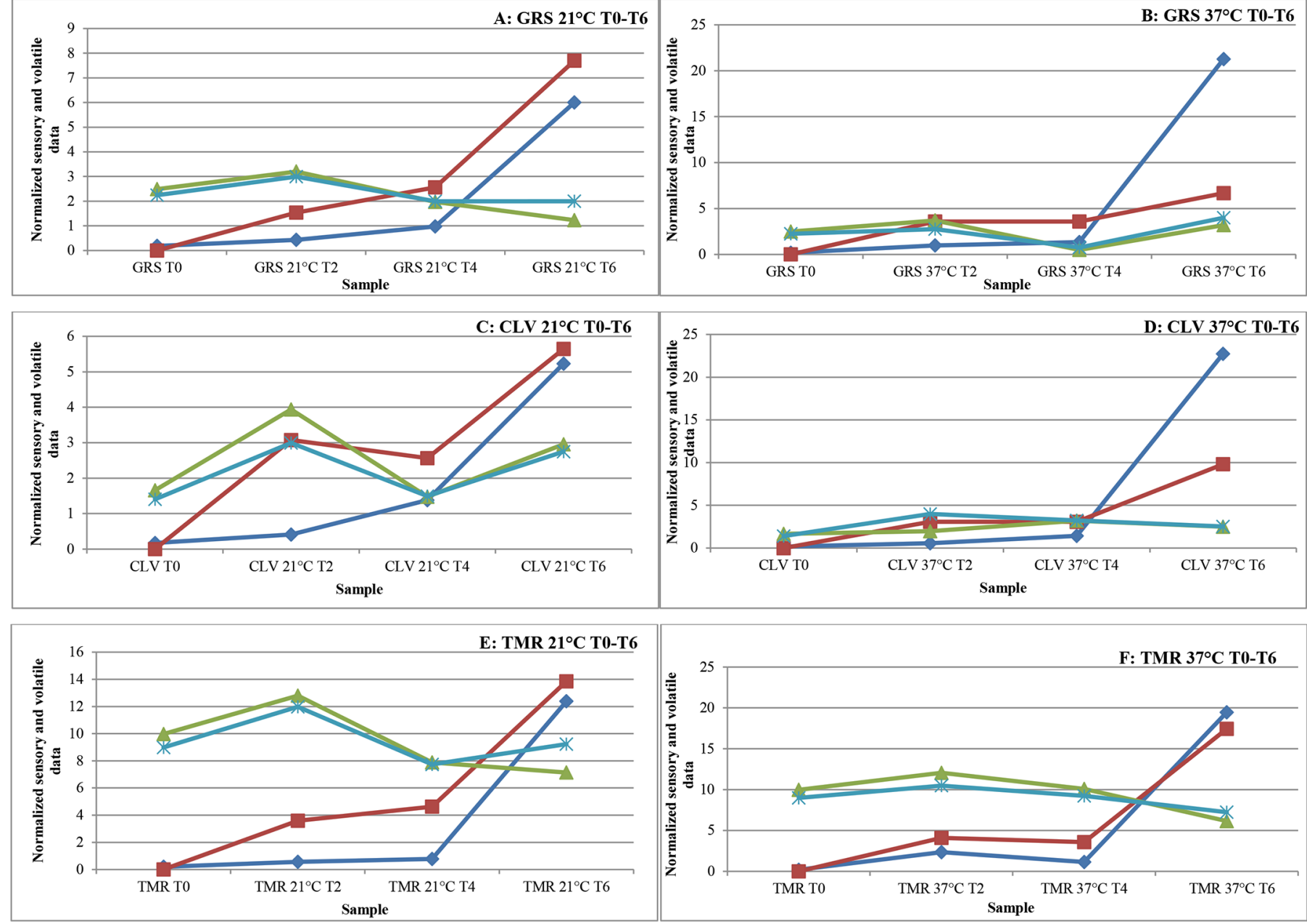

Figure 2. Graphs illustrating the increase in painty flavor and hexanal and the decrease in buttery/toffee flavor and aroma in whole milk powders derived from (A) grass (GRS) stored at $21^{\circ} \mathrm{C}$ and (B) GRS $37^{\circ} \mathrm{C}$; (C) clover $(\mathrm{CLV}) 21^{\circ} \mathrm{C}$ and $(\mathrm{D}) \mathrm{CLV} 37^{\circ} \mathrm{C}$; and $(\mathrm{E}) \mathrm{TMR} 21^{\circ} \mathrm{C}$ and (F) TMR $37^{\circ} \mathrm{C}$ during 6 mo of storage (T0-T6). Normalized data were used for the purpose of these graphs. 

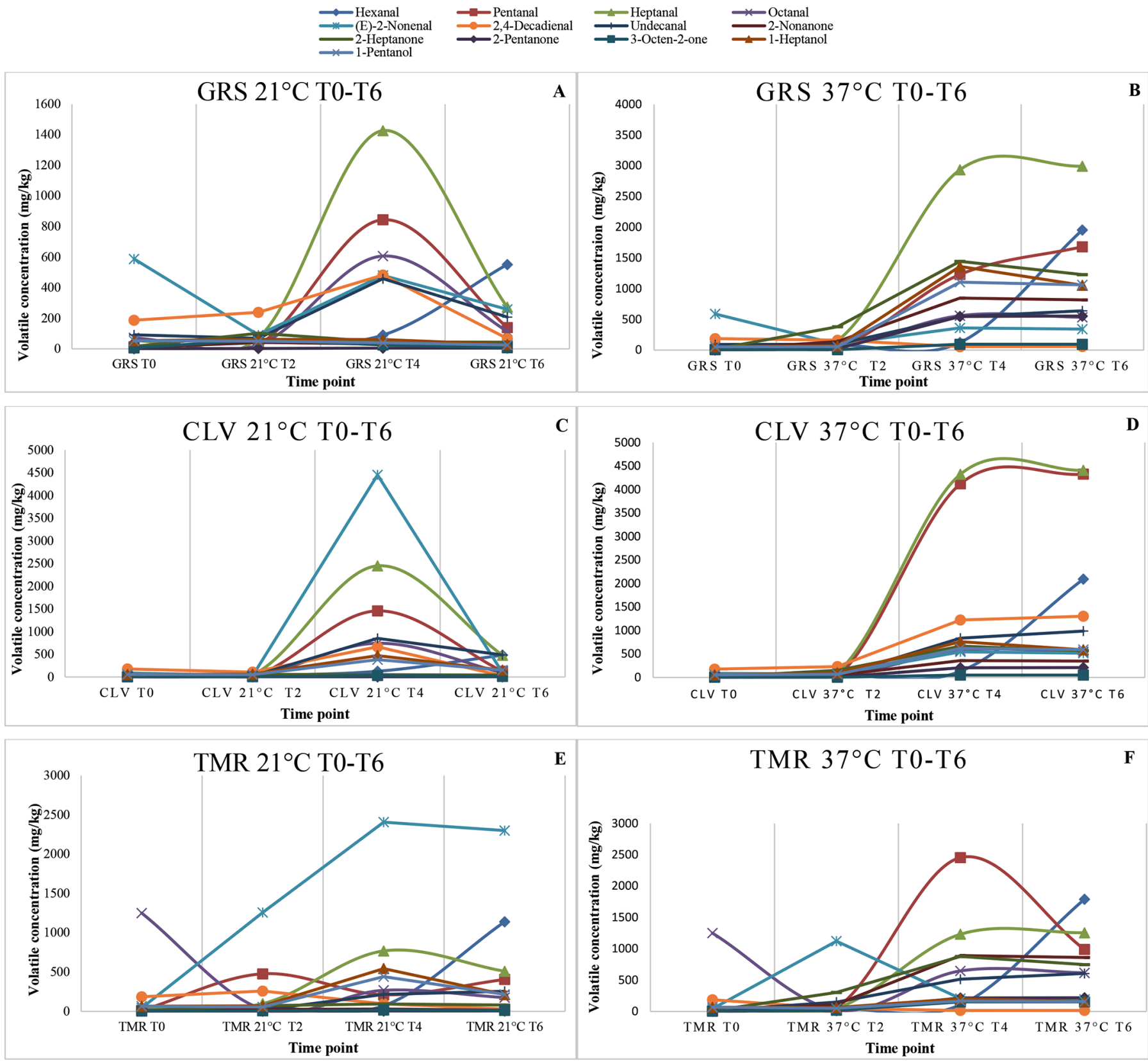

Figure 3. Graphs illustrating the concentrations $(\mathrm{mg} / \mathrm{kg})$ of the 13 selected volatile compounds in (A) grass (GRS) whole milk powder (WMP) stored at $21^{\circ} \mathrm{C}$ during 6 mo of storage (T0-T6); (B) clover (CLV) WMP $21^{\circ} \mathrm{C}$; (C) TMR WMP $21^{\circ} \mathrm{C}$; (D) GRS WMP $37^{\circ} \mathrm{C}$; (E) CLV WMP $37^{\circ} \mathrm{C}$; and (F) TMR WMP $37^{\circ} \mathrm{C}$.

compounds reached their highest concentrations at $\mathrm{T} 4$ and decreased by T6, except for 2,4-decadienal and (E)-2-nonenal, which were highest at T0 (Figure 3B and Supplemental Table S4B, http://hdl.handle.net/ 11019/2424).

In CLV WMP stored at $21^{\circ} \mathrm{C}$, similar trends to those of the GRS WMP stored at $21^{\circ} \mathrm{C}$ were observed. Concentrations of hexanal, pentanal, heptanal, octanal,
(E)-2-nonenal, 2,4-decadienal, undecanal, 2-nonanone, 3-octen-2-one, 1-heptanol, and 1-pentanol increased from $\mathrm{T} 0$ to $\mathrm{T} 4$ and decreased thereafter, apart from hexanal, which continued to increase to T6 (Figure 3C and Supplemental Table S4C, http://hdl.handle.net/ $11019 / 2424)$. For CLV WMP stored at $37^{\circ} \mathrm{C}$, the aldehydes hexanal, pentanal, and heptanal reached much higher concentrations than in CLV WMP stored at 
$21^{\circ} \mathrm{C}$. Similar to GRS WMP stored at $37^{\circ} \mathrm{C}$, hexanal, pentanal, heptanal, and 2,4-decadienal continued to increase after $\mathrm{T} 4$ in the CLV WMP stored at $37^{\circ} \mathrm{C}$. The other 9 volatile compounds remained the same or decreased by T6 [octanal, (E)-2-nonenal, undecanal, 2-nonanone, 2-heptanone, 2-pentanone, 3-octen-2-one, 1-heptanol, and 1-pentanol; Figure 3D and Supplemental Table S4D, http://hdl.handle.net/11019/2424].

In TMR WMP, (E)-2-nonenal was higher in samples stored at $21^{\circ} \mathrm{C}$ than $37^{\circ} \mathrm{C}$; it increased gradually from T0 to T4 and then decreased by T6. In TMR WMP stored at $21^{\circ} \mathrm{C}(\mathrm{E})-2$-nonenal was the most abundant compound at a concentration of $2,407 \mathrm{mg} / \mathrm{kg}$ at T4. In the $37^{\circ} \mathrm{C}$ samples it reached its highest concentration at T2 $(1,122 \mathrm{mg} / \mathrm{kg})$ but decreased thereafter. For TMR WMP stored at $21^{\circ} \mathrm{C}$, hexanal, undecanal, and 2 -pentanone increased gradually from T0 to T6; the remaining 10 compounds either decreased [heptanal, (E)2-nonenal, 2-nonanone, 2-heptanone, 3-octen-2-one, 1-heptanol, and 1-pentanol] from T4 to T6 or fluctuated throughout storage (pentanal, octanal, and 2,4-decadienal; Figure 3E and Supplemental Table S4E, http:// hdl.handle.net/11019/2424). In TMR WMP stored at $37^{\circ} \mathrm{C}$ hexanal, heptanal, undecanal, and 2-pentanone increased from T0 to T6. The remaining 8 volatile compounds either decreased (pentanal, 2-heptanone, 1-heptanol, and 1-pentanol) from $\mathrm{T} 4$ to T6, fluctuated throughout storage (octanal), plateaued (3-octen2 -one), or reached their highest concentration early in storage and began to decrease thereafter [2,4-decadienal and (E)-2-nonenal; Figure 3F and Supplemental Table S4F, http://hdl.handle.net/11019/2424]. As previously mentioned, compounds that begin to decrease in storage are likely degraded or catabolized, in many cases to other volatile compounds. Thus, for most volatile LO compounds in this study, the rate of formation was exceeded by degradation after 4-mo storage, presumably due to a lack of available FA substrate or other factors inhibiting the primary LO process. Maximum levels of some compounds were reached more rapidly in the WMP stored at $37^{\circ} \mathrm{C}$ due to the increased temperature.

\section{Correlations Between Volatile Components and Sensory Attributes}

Pearson correlation analysis was carried out on the sensory and volatile data using SPSS. Numerous positive correlations were evident between volatile components and sensory attributes, but only strong correlations $\geq 0.7$ are reported here. Hay-like aroma was significantly $(P<0.001)$ correlated with barnyard/ cowy aroma (0.794), grassy aroma (0.734), cooked milk flavor (0.777), grassy flavor (0.956), hay-like flavor
(0.930), and barnyard/cowy flavor (0.792). Buttery/ toffee aroma was correlated with dairy sweet aroma (0.809), dairy sweet flavor (0.969), and buttery/toffee flavor (0.969). Painty aroma was correlated with painty flavor (0.791), painty flavor aftereffect (0.812), and metallic flavor aftereffect (0.754). Metallic aroma was correlated with increases in solvent-like flavor (0.828). Creamy flavor was correlated with viscosity (0.897), creaminess $(0.870)$, and astringency $(-0.776)$. Painty flavor was correlated with solvent-like flavor (0.716) and increasing concentrations of hexanal (0.793). Painty flavor aftereffect was also correlated with hexanal (0.749). Increases in concentrations of pentanal were correlated with increases in heptanal (0.911), 2,4-decadienal (0.750), and undecanal (0.843). Increases in heptanal were also correlated with increases in undecanal (0.784), 1-heptanol (0.784), and 1-pentanol (0.794). 2 -Nonanone was significantly correlated with increases in levels of 2-heptanone (0.924), 2-pentanone (0.874), and 3-octen-2-one (0.923). As observed with heptanal, 2-heptanone and 2-pentanone were correlated with increases in the alcohol compounds 1-heptanol (0.750 and 0.858 , respectively) and 1-pentanol (0.756 and 0.880, respectively). 2-Heptanone was also correlated with 3-octen-2-one (0.743), and 1-heptanol was correlated with 1-pentanol (0.991).

The key factor influencing the perception of LO compounds is their odor thresholds (the lowest concentration of a compound perceivable by the human nose), which vary considerably and also depend upon the matrix effect (the binding of compounds to components of the sample affecting their release). The highest concentrations of the aldehydes hexanal, pentanal, heptanal were observed in GRS and CLV WMP stored at $37^{\circ} \mathrm{C}$ at $\mathrm{T} 4$ and $\mathrm{T} 6(>1,500 \mathrm{mg} / \mathrm{kg}$; Figure $2 \mathrm{~B}$ and $2 \mathrm{D})$. These compounds were consistently higher in GRS and CLV WMP compared with TMR WMP. Conversely, painty attributes, which are commonly associated with increases in hexanal were correlated more with TMR WMP toward the latter stages of storage. Although the results of this study show correlations between painty attributes and concentrations of hexanal, it is unlikely that one single compound is responsible for specific attributes when numerous other odor-active compounds are present (Kobayashi and Nishimura, 2014). However, increases in the volatile compounds evaluated in this study are good indicators of LO state, but perhaps other approaches such as olfactometry are required to absolutely associate the concentration of specific volatiles with specific aroma descriptors. Overall, aldehydes ( $\geq 8$ carbons) and branched-chain aldehydes were most correlated with CLV WMP. The ketone compounds 2-nonanone, 2-heptanone, 2-pentanone, 
and 3-octen-2-one were consistently higher in GRS and TMR WMP samples stored at $37^{\circ} \mathrm{C}$ throughout the study, whereas the alcohol compounds 1-heptanol and 1-pentanol were highest in GRS and CLV stored at $37^{\circ} \mathrm{C}$. Concentrations of the FA (C4:0-C12:0) were higher overall in GRS and CLV WMP compared with TMR WMP (Table 1), which may have influenced LO susceptibility, particularly in relation to aldehyde formation. The concentrations of oleic acid were not significantly different between the WMP samples, but it is thought to be a major precursor for hexanal formation. Linoleic acid was significantly $(P<0.05)$ higher in TMR WMP and is also a precursor of hexanal, in addition to pentanal and 3-octen-2-one. Linoleic acid likely influenced the higher levels of 3-octen-2-one in TMR WMP, but because both hexanal and pentanal were higher in pasture-derived WMP, other sources or factors must be influencing their formation, such as the presence of natural pro- and antioxidants. $\alpha$-Linolenic acid (C18:3n-3) has been shown to produce hexanal by Tawfik et al. (2017) and was significantly higher $(P<$ $0.05)$ in pasture-derived WMP (CLV > GRS). Eicosanoic acid (C20:0) and heneicosanoic acid (C21:0), $\alpha$-linolenic acid (CLA; c10t12), and CLA (c9t11) were also significantly $(P<0.05)$ different based on diet and likely also affected aldehyde formation. In addition, CLA has been shown to oxidize more rapidly than linoleic acid, supporting evidence that the conjugated double bond is more susceptible to oxidation than a nonconjugated double bond, thus facilitating volatile compound formation and release (Moon et al., 2008).

\section{CONCLUSIONS}

The main finding from this study was that the bovine feeding system pasture (GRS and CLV) versus nonpasture (TMR) significantly affected the TFA, FFA, volatile profile, and sensory attributes of WMP. Pasturederived WMP (GRS and CLV) were best correlated with creamy color, dairy sweet aroma, and hay-like attributes, whereas nonpasture-derived WMP (TMR) was best correlated with white color and buttery/toffee and painty attributes. Buttery/toffee attributes were found to be more closely correlated with TMR WMP. Increases in many of the volatiles studied were evident during storage at both $21^{\circ} \mathrm{C}$ and $37^{\circ} \mathrm{C}$, with some compounds peaking at $\mathrm{T} 4$ and then plateauing or decreasing slightly by T6, likely due to degradation exceeding formation. Pasture-derived WMP (GRS and CLV) were found to be more susceptible to LO from a volatile perspective, particularly in relation to aldehyde development, possibly due to increased concentrations of CLA and $\alpha$-linolenic acid. Pleasant attributes, pos- sibly associated with Maillard reaction products were perceivable in the WMP at the beginning of the study but became masked by LO compounds with off-flavors by T4. Correlations were made between concentrations of hexanal and painty attributes, but it is unlikely that a single compound was responsible for these attributes. Regardless of this, however, the recommended shelf life for WMP once opened was $<4$ mo from a sensory perspective.

\section{ACKNOWLEDGMENTS}

The authors sincerely thank David Mannion for his advice and technical support throughout the study, and Gloria Ho (Teagasc Food Research Center, Moorepark, Fermoy, Co. Cork, Ireland) for carrying out the fatty acid analysis on the powder samples. The authors also thank each of the sensory panelists for their effort throughout the study. Holly Clarke is in receipt of a Teagasc Walsh Scholarship (Reference No: 2016071). This research was funded by Teagasc-Project 0044, Profiling Milk from Grass. The authors declare no conflict of interest.

\section{REFERENCES}

Bastos, D. M., É. Monaro, É. Siguemoto, and M. Séfora. 2012. Maillard reaction products in processed food: Pros and cons. Pages 281-300 in Food Industrial Processes-Methods and Equipment. INTECH Open.

Cesa, S., M. A. Casadei, F. Cerreto, and P. Paolicelli. 2015. Infant milk formulas: Effect of storage conditions on the stability of powdered products towards autoxidation. Foods 4:487-500. https://doi.org/ 10.3390 /foods4030487.

Chapman, K. W., H. T. Lawless, and K. J. Boor. 2001. Quantitative descriptive analysis and principal component analysis for sensory characterization of ultrapasteurized milk. J. Dairy Sci. 84:12-20. https://doi.org/10.3168/jds.S0022-0302(01)74446-3.

CIE (Commission Internationale de l'Éclairage). 1978. Recommendations on uniform color spaces, color difference equations, psychometric color terms. CIE Publication 15, Suppl. 2. Colorimetry, Bureau Central de la CIE.

Clarke, H. J., C. Griffin, D. K. Rai, T. F. O'Callaghan, M. G. O'Sullivan, J. P. Kerry, and K. N. Kilcawley. 2020a. Dietary compounds influencing the sensorial, volatile and phytochemical properties of bovine milk. Molecules 25:26. https://doi.org/10.3390/ molecules25010026.

Clarke, H. J., D. T. Mannion, M. G. O'Sullivan, J. P. Kerry, and K. N. Kilcawley. 2019. Development of a headspace solid-phase microextraction gas chromatography mass spectrometry method for the quantification of volatiles associated with lipid oxidation in whole milk powder using response surface methodology. Food Chem. 292:75-80. https://doi.org/10.1016/j.foodchem.2019.04.027.

Clarke, H. J., M. G. O'Sullivan, J. P. Kerry, and K. N. Kilcawley. 2020b. Correlating volatile lipid oxidation compounds with consumer sensory data in dairy based powders during storage. Antioxidants 9:338. https://doi.org/10.3390/antiox9040338.

De Jong, C., and H. T. Badings. 1990. Determination of free fatty acids in milk and cheese procedures for extraction, clean up, and capillary gas chromatographic analysis. J. High Resolut. Chromatogr. 13:94-98. https://doi.org/10.1002/jhrc.1240130204. 
Decker, E. A., R. J. Elias, and D. J. McClements. 2010. Oxidation in foods and beverages and antioxidant applications. In Management in Different Industry Sectors. Woodhead Publishing.

Deeth, H. C. 2006. Lipoprotein lipase and lipolysis in milk. Int. Dairy J. 16:555-562. https://doi.org/10.1016/j.idairyj.2005.08.011.

Drake, M. A., Y. Karagul-Yuceer, K. R. Cadwallader, G. V. Civille, and P. S. Tong. 2003. Determination of the sensory attributes of dried milk powders and dairy ingredients. J. Sens. Stud. 18:199 216. https://doi.org/10.1111/j.1745-459X.2003.tb00385.x.

Early, R. 2012. Dairy products and milk-based food ingredients. Pages 417-445 in Natural Food Additives, Ingredients and Flavourings. D. Baines and R. Seal, ed. Woodhead Publishing.

Eriksson, C. E. 1982. Lipid oxidation catalysts and inhibitors in raw materials and processed foods. Food Chem. 9:3-19. https://doi .org/10.1016/0308-8146(82)90065-6.

Faulkner, H., T. F. O'Callaghan, S. McAuliffe, D. Hennessy, C. Stanton, M. G. O'Sullivan, J. P. Kerry, and K. N. Kilcawley. 2018. Effect of different forage types on the volatile and sensory properties of bovine milk. J. Dairy Sci. 101:1034-1047. https://doi.org/10 $.3168 /$ jds.2017-13141.

Gulati, A., N. Galvin, D. Hennessy, S. McAuliffe, M. O'Donovan, J. J. McManus, M. A. Fenelon, and T. P. Guinee. 2018. Grazing of dairy cows on pasture versus indoor feeding on total mixed ration: Effects on low-moisture part-skim Mozzarella cheese yield and quality characteristics in mid and late lactation. J. Dairy Sci. 101:8737-8756. https://doi.org/10.3168/jds.2018-14566.

Havemose, M. S., M. R. Weisbjerg, W. L. P. Bredie, H. D. Poulsen, and J. H. Nielsen. 2006. Oxidative stability of milk influenced by fatty acids, antioxidants, and copper derived from feed. J. Dairy Sci. 89:1970-1980. https://doi.org/10.3168/jds.S0022-0302(06)72264 -0 .

Hedegaard, R. V., D. Kristensen, J. H. Nielsen, M. B. Frøst, H. Østdal, J. E. Hermansen, M. Kröger-Ohlsen, and L. H. Skibsted. 2006. Comparison of descriptive sensory analysis and chemical analysis for oxidative changes in milk. J. Dairy Sci. 89:495-504.

Hidalgo, F. J., and R. Zamora. 2004. Strecker-type degradation produced by the lipid oxidation products 4,5-epoxy-2-alkenals. J. Agric. Food Chem. 52:7126-7131. https://doi.org/10.1021/jf048883r.

IDF. 1997. Standard 99C: Sensory evaluation of dairy products by scoring reference methodology. International Dairy Federation.

Javidipour, I., and M. C. Qian. 2008. Volatile component change in whey protein concentrate during storage investigated by headspace solid-phase microextraction gas chromatography. Dairy Sci. Technol. 88:95-104. https://doi.org/10.1051/dst:2007010.

Kelly, M. L., E. S. Kolver, D. E. Bauman, M. E. Van Amburgh, and L. D. Muller. 1998. Effect of intake of pasture on concentrations of conjugated linoleic acid in milk of lactating cows. J. Dairy Sci. $81: 1630-1636$

Kilcawley, K. N., H. Faulkner, H. J. Clarke, M. G. O'Sullivan, and J. P. Kerry. 2018. Factors influencing the flavour of bovine milk and cheese from grass based versus non-grass based milk production systems. Foods 7:37. https://doi.org/10.3390/foods7030037.

Kobayashi, N., and O. Nishimura. 2014. Availability of detection frequency method using three-port gas chromatography-olfactometry for rapid comparison of whole milk powders. Food Sci. Technol. Res. 20:809-814. https://doi.org/10.3136/fstr.20.809.

Labuza, T., and W. Baiser. 1992. The kinetics of nonenzymatic browning. Pages 595-649 in Physical Chemistry of Foods. H. Schwartzber, ed. Marcel Dekker Inc.

Liu, S., R. Zhang, R. Kang, J. Meng, and C. Ao. 2016. Milk fatty acids profiles and milk production from dairy cows fed different forage quality diets. Anim. Nutr. 2:329-333. https://doi.org/10.1016/j .aninu.2016.08.008.

Lloyd, M. A., M. A. Drake, and P. D. Gerard. 2009a. Flavor variability and flavor stability of US-produced whole milk powder. J. Food Sci. 74:S334-S343. https://doi.org/10.1111/j.1750-3841.2009 .01299.x.

Lloyd, M. A., S. J. Hess, and M. A. Drake. 2009b. Effect of nitrogen flushing and storage temperature on flavor and shelf-life of whole milk powder. J. Dairy Sci. 92:2409-2422. https://doi.org/10.3168/ jds.2008-1714.

Magan, J. B., J. T. Tobin, T. F. O'Callaghan, A. L. Kelly, M. A. Fenelon, D. Hennessy, and N. A. McCarthy. 2019. Physicochemical properties of whole milk powder derived from cows fed pasture or total mixed ration diets. J. Dairy Sci. 102:9611-9621. https://doi .org/10.3168/jds.2019-16415.

Mannion, D. T., A. Furey, and K. N. Kilcawley. 2016. Free fatty acids quantification in dairy products. Int. J. Dairy Technol. 69:1-12. https://doi.org/10.1111/1471-0307.12301.

Mannion, D. T., A. Furey, and K. N. Kilcawley. 2019. Development and validation of a novel free fatty acid butyl ester gas chromatography method for the determination of free fatty acids in dairy products. J. Agric. Food Chem. 67:499-506. https://doi.org/10 .1021 acs.jafc. 8 b05462.

Martin, B., I. Verdier-Metz, S. Buchin, C. Hurtaud, and J.-B. Coulon. 2005. How do the nature of forages and pasture diversity influence the sensory quality of dairy livestock products? Anim. Sci. $81: 205-212$.

Moon, H.-S., H.-G. Lee, C.-S. Chung, Y.-J. Choi, and C.-S. Cho. 2008. Physico-chemical modifications of conjugated linoleic acid for ruminal protection and oxidative stability. Nutr. Metab. (Lond.) 5:16. https://doi.org/10.1186/1743-7075-5-16.

Muir, D. D. 1996. The shelf-life of dairy products: 3. Factors influencing intermediate and long life dairy products. Int. J. Dairy Technol. 49:67-72. https://doi.org/10.1111/j.1471-0307.1996.tb02493 $\mathrm{x}$.

Neilson, A. P., H. F. Pahulu, L. V. Ogden, and O. A. Pike. 2006. Sensory and nutritional quality of dehydrated potato flakes in longterm storage. J. Food Sci. 71:S461-S466. https://doi.org/10.1111/ j.1750-3841.2006.00084.x.

O'Callaghan, T. F., D. Hennessy, S. McAuliffe, K. Kilcawley, M. O'Donovan, P. Dillon, R. Ross, and C. Stanton. 2016. Effect of pasture versus indoor feeding systems on raw milk composition and quality over an entire lactation. J. Dairy Sci. 99:9424-9440. https://doi.org/10.3168/jds.2016-10985.

O'Callaghan, T. F., D. Mannion, D. Apopei, N. A. McCarthy, S. A. Hogan, K. N. Kilcawley, and M. Egan. 2019. Influence of supplemental feed choice for pasture-based cows on the fatty acid and volatile profile of milk. Foods 8:137. https://doi.org/10.3390/ foods 8040137 .

O'Callaghan, T. F., D. T. Mannion, D. Hennessy, S. McAuliffe, M. G. O'Sullivan, N. Leeuwendaal, T. P. Beresford, P. Dillon, K. N. Kilcawley, J. J. Sheehan, R. P. Ross, and C. Stanton. 2017. Effect of pasture versus indoor feeding systems on quality characteristics, nutritional composition, and sensory and volatile properties of fullfat Cheddar cheese. J. Dairy Sci. 100:6053-6073. https://doi.org/ 10.3168/jds.2016-12508

Páez, R., N. Pensel, N. Sabbag, M. Taverna, A. Cuatrin, and C. Zalazar. 2006. Changes in free fatty acid composition during storage of whole milk powder. Int. J. Dairy Technol. 59:236-241. https://doi .org/10.1111/j.1471-0307.2006.00270.x.

Park, C. W., M. A. Stout, and M. Drake. 2016. The effect of spraydrying parameters on the flavor of nonfat dry milk and milk protein concentrate 70\%. J. Dairy Sci. 99:9598-9610. https://doi.org/ 10.3168/jds.2016-11692.

Patton, S. 1955. Browning and associated changes in milk and its products: A review. J. Dairy Sci. 38:457-478. https://doi.org/10 .3168/jds.S0022-0302(55)95000-1.

R Core Team. 2013. R: A language and environment for statistical computing. R Foundation for Statistical Computing.

Romeu-Nadal, M., A. Castellote, and M. López-Sabater. 2004. Headspace gas chromatographic method for determining volatile compounds in infant formulas. J. Chromatogr. A 1046:235-239. https: //doi.org/10.1016/j.chroma.2004.06.032.

Rozycki, S. D., M. S. Pauletti, S. C. Costa, A. M. Piagentini, and M. P. Buera. 2007. The kinetics of colour and fluorescence development in concentrated milk systems. Int. Dairy J. 17:907-915. https://doi.org/10.1016/j.idairyj.2006.12.006. 
Semeniuc, C., M. A. Rotar, C. Gus, C. Bele, F. Dulf, S. A. Socaci, and C. Laslo. 2008. Fatty acids profile of two types of dry dairy products: Whole milk powder and infant formula to obtaining. J. Agroaliment. Processes Technol. 14:133-136.

Stone, H., and J. L. Sidel. 1998. Quantitative descriptive analysis: Developments, applications, and the future. Food Technol. J. $52: 48-52$.

Tawfik, M. M., K. T. Yamato, T. Kohchi, T. Koeduka, and K. Matsui. 2017. n-Hexanal and (Z)-3-hexenal are generated from arachidonic acid and linolenic acid by a lipoxygenase in Marchantia polymorpha L. Biosci. Biotechnol. Biochem. 81:1148-1155. https:/ /doi.org/10.1080/09168451.2017.1285688.

Tunick, M. H., S. K. Iandola, and D. L. Van Hekken. 2013. Comparison of SPME methods for determining volatile compounds in milk, cheese, and whey powder. Foods 2:534-543. https://doi.org/ 10.3390 /foods 2040534

Van Aardt, M., S. E. Duncan, J. E. Marcy, T. E. Long, S. F. O'Keefe, and S. R. Nielsen-Sims. 2005. Aroma analysis of light-exposed milk stored with and without natural and synthetic antioxidants. J. Dairy Sci. 88:881-890.

Wright, B. J., S. E. Zevchak, J. M. Wright, and M. A. Drake. 2009. The impact of agglomeration and storage on flavor and flavor stability of whey protein concentrate $80 \%$ and whey protein isolate. J. Food Sci. 74:S17-S29. https://doi.org/10.1111/j.1750-3841.2008 .00975.x.

\section{ORCIDS}

H. J. Clarke @ https://orcid.org/0000-0003-3675-3904

D. Hennessy (1) https://orcid.org/0000-0002-7375-3754

T. F. O'Callaghan (๑) https://orcid.org/0000-0003-2684-7253

K. N. Kilcawley ๑ https://orcid.org/0000-0003-4048-8883 